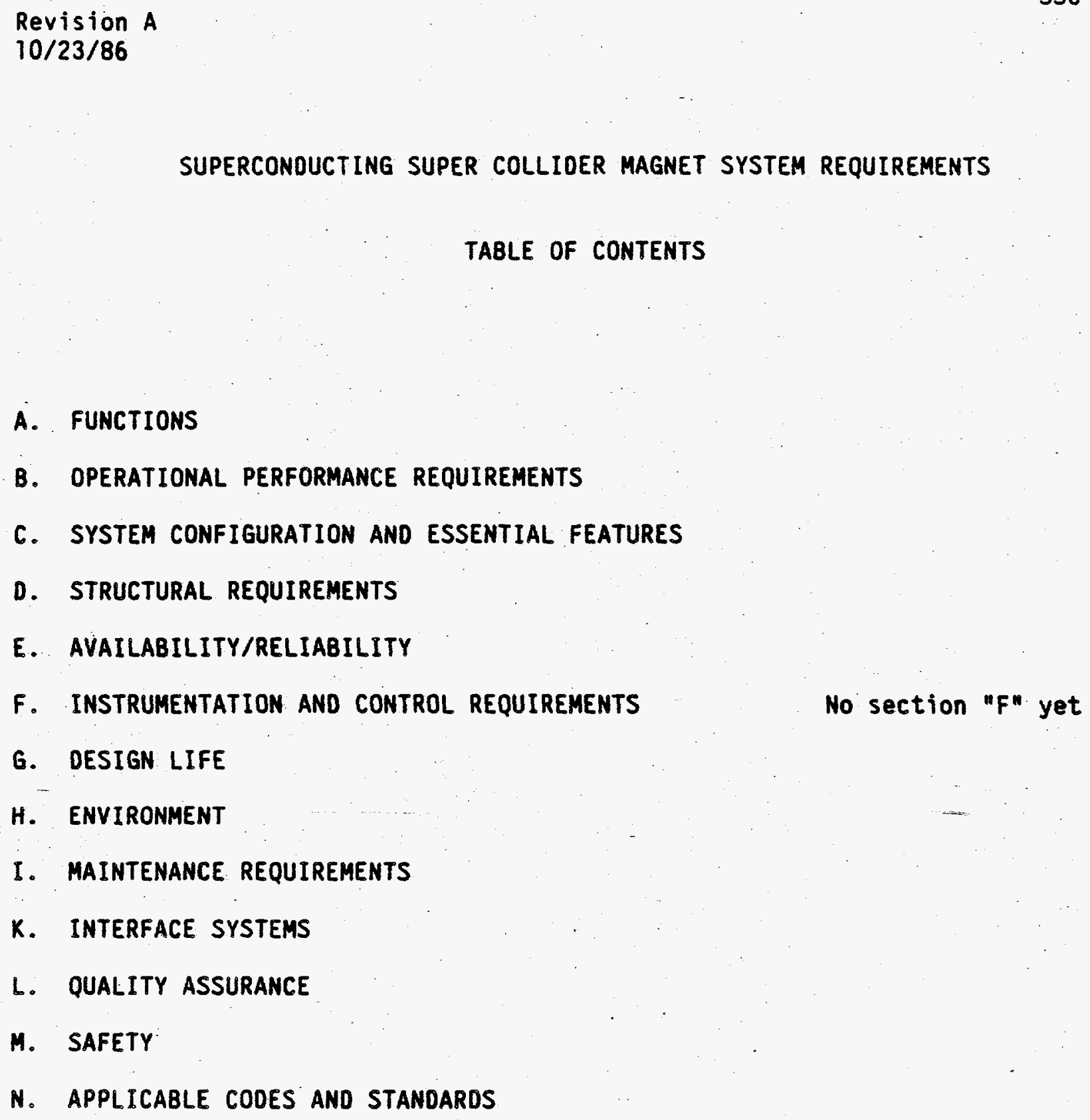

TABLE OF CONTENTS

A. FUnCTIONS

B. OPERATIONAL PERFORMANCE REQUIREMENTS

C. SYSTEM CONFIGURATION ANO ESSENTIAL FEATURES

D. STRUCTURAL REQUIREMENTS

E. AVAILABILITY/RELIABILITY

F. INSTRUMENTATION AND CONTROL REQUIREMENTS

No section "F" yet

G. DESIGN LIFE

H. ENVIRONMENT

I. MAINTENANCE REQUIREMENTS

K. INTERFACE SYSTEMS

L. QUALITY ASSURANCE

M. SAFETY

N. APPLICABLE CODES AND STANDARDS

\title{
Approva 1:
}

APPROVED FOR RELEASE OR

- PUBLICATION - O.R. PATENT GROUP 
MAGNET SYSTEM*

\title{
A. Function
}

The Magnet System function is to provide high quality magnetic fields to steer and confine two proton beams along circular orbits approximately 52 miles in circumference. The two beams travel for most of the circumference in separate parallel vacuum and cryostat enclosures, one above the other.

B. Operational Performance Requirements

The magnet is to provide a 6.6 Tesla steady uniform magnetic field. Field quality shall be sufficient to produce no impact on the beam lifetime over the entire energy of the machine i.e., from 1 TeV to $20 \mathrm{TeV}$. The magnitude of the random and systematic errors shall be controlled to a value of multipole coefficients specified in Table I. Table I reflects field corrections by trim coil. Table I does not include superconductor magnetization effects. The magnetization effects will be corrected by windings in the trim coil.

\section{DISCLAIMER}

\begin{abstract}
This report was prepared as an account of work sponsored by an agency of the United States Government. Neither the United States Government nor any agency thereof, nor any of their employees, makes any warranty, express or implied, or assumes any legal liability or responsibility for the accuracy, completeness, or usefulness of any information, apparatus, product, or process disclosed, or represents that its use would not infringe privately owned rights. Reference herein to any specific commercial product, process, or service by trade name, trademark, manufacturer, or otherwise does not necessarily constitute or imply its endorsement, recommendation, or favoring by the United States Government or any agency thereof. The views and opinions of authors expressed herein do not necessarily state or reflect those of the United States Government or any agency thereof.
\end{abstract}

* This version is. limited to dipoles. Requirements for other elements to be added later. 
TABLE I

Specified Tolerances

\begin{tabular}{cccc} 
Multipole & & Random & Systematic \\
\cline { 1 - 1 }$a_{1}$ & & 0.7 & 0.2 \\
$a_{2}$ & 0.6 & 0.1 \\
$a_{3}$ & 0.7 & 0.2 \\
$a_{4}$ & 0.2 & 0.2 \\
$a_{5}$ & 0.2 & -- \\
$a_{6}$ & 0.1 & - \\
$a_{7}$ & 0.2 & -- \\
$a_{8}$ & 0.1 & - \\
& & \\
$b_{1}$ & 0.7 & 0.2 \\
$b_{2}$ & 2.0 & 1.0 \\
$b_{3}$ & 0.3 & 0.1 \\
$b_{4}$ & 0.7 & 0.2 \\
$b_{5}$ & 0.1 & 0.02 \\
$b_{6}$ & 0.2 & 0.04 \\
$b_{7}$ & 0.2 & 0.06 \\
$b_{8}$ & 0.1 & 0.1 \\
$\Delta(B L) / B L$, & RMS $\pm 3 \times 10^{-4}$ &
\end{tabular}

Table II

Beam Tube Correction Winding Requirements

$\begin{array}{lll}\text { b2 } & \geqq 4 \text { units } \\ \text { b3 } & \geqq 0.4 \text { unit - full length equivalent at } 6.6 \mathrm{~T} \\ \text { b4 } & \geqq 0.4 \text { unit } \\ \text { Lwinding } & \geqq \text { for } b_{2}=8.3 \mathrm{~m}\end{array}$




\section{DISCLAIMER}

Portions of this document may be illegible in electronic image products. Images are produced from the best available original document. 
Superconducting Magnets shall utilize a minimum diameter of NbTi alloy strands and shall be capable of producing full field at an operating temperature of $4.35 \mathrm{~K}$.

Each magnet shall be provided with a quench protection system which shall $\therefore$ limit temperature during quench to a maximum of $550 \mathrm{~K}$.

The assembly shall be capable of withstanding eddy current effects resulting from a magnet discharge from full field in $300 \mathrm{milliseconds.}$

The coil shall have a $4 \mathrm{~cm}$ inside diameter. After space is allowed for bore tube, electrical insulation, correction winding and helium paths, the aperture for the beam shall be $3 \mathrm{~cm}$ minimum.

To avoid significant loss of beam particles through nuclear interactions with residual gas, a partial pressure of hydrogen of less than $10^{-8}$ Torr (room temp $\mathrm{N}_{2}$ equivalent), and a partial pressure of other gasses of less than $5 \times 10^{-10}$ Torr (room temp $N_{2}$ equivalent) is required when the synchrotron radiation power linear density in the tube is $0.1 \mathrm{w} / \mathrm{m}$. The insulating vacuum of $10^{-6}$ Torr shall be maintained within the cryostat envelope with components within cryostat assembly at their operating temperature. The supercritical helium at $4.35 \mathrm{~K}$ and $4 \mathrm{~atm}$ shall pass through magnets to remove heat and keep the coil at or below $4.35 \mathrm{~K}$. The heat leak for completed magnet assembly shall not exceed 27.0 watts for $80 \mathrm{~K}, 3.30$ watts for $20 \mathrm{~K}$, and 3.07 watts for $4 \mathrm{~K}$ system as shown in Table III below: 
TABLE III

Heat Leak Budget, Referred to Individual Dipole

$4.15 K \quad 20 K \quad \begin{gathered}84 K \\ \text { (watts) }\end{gathered}$

Dipole static

Infrared

Supports

Conn. and Inst.

Subtotal static
0.05

0.12

0.15

0.32

2.34

Synch rad

0.10

Splices

0.10

Beam-gas

Beam-microwave

Subtotal beam-related

0.2

2.75

Dipole beam-related

Dipole Totals

3.07

17.7

7.2

$\underline{2.1}$

27.0

2.16

0.82

$\underline{0.32}$

3.30

27.0

The cooldown requirements are that a section $(1000 \mathrm{~m})$ of the system must be cooled and filled to the operating point in 48 hours as part of the magnet change scenario. Thus cooldown of this section to $80 \mathrm{~K}$ must occur in no more than 36 hours and the individual dipole will be cooled rapidiy. Any restrictions on cooldown rate on any part of the magnet system must be avoided. The warmup shall be accomplished in 24 hours. This warmup shall be accomplished uniformly by internal heaters. 


\section{System Configuration and Essential Features}

\section{General}

The Magnet System consists of one-in-one two layer "Cos $\theta$ " dipole magnets approximately 16.6 meters long (magnetic length), arranged in over/under configuration. To accommodate interconnections, $80 \mathrm{~cm}$ between "magnetic" dipole ends is provided. The overall slot length is about $17.34 \mathrm{~m}$. Vertical center-to-center spacing between two magnet beam lines should be $70 \mathrm{~cm}$ except for crossing regions.

Magnet assembly consists of two major subsystems, $i_{\text {. }} e_{\text {, }}$ cold mass and cryostat. The cold mass consists of the beam tube and collared coil assembly that is contained in a yoke structure and helium containment shell all at $4.35 \mathrm{~K}$. It is cooled to this temperature by a flow of supercritical helium through holes in the yoke structure, and through the annular space between trim coils and inner layer of the main dipole coil. The helium permeates the superconducting layer of the dipole coil and electrical insulation.

The cold mass of the magnet is supported within the cryostat by low-heatleak "folded posts" made of low conductivity materials. Additional thermal insulation is provided by radiation shields, the outermost cooled by a liquid nitrogen circuit, and an intermediate shield cooled by a $20 \mathrm{~K}$ He line. Blankets of multilayer superinsulation occupy spaces on both sides of the thermal shields. The insulating vacuum is contained by a minimum envelope vessel and is maintained by cryopumping within the cryostat.

\section{Beam Tubes}

The cold beam tube separates the helium magnet coolant from the beam vacuum chamber. Enough aperture must be provided for beam injection, acceleration, and storage purposes. The inside diameter of each beam tube should not be less than $30 \mathrm{~mm}$. The inside diameter of the coil 
is $40 \mathrm{~mm}$. The tube is made of stainless steel with copper coating on the inside diameter, or aluminum*. The outside diameter of the tube supports distributed sextupole/decapole correction coils; they are keyed to the pole spacers to maintain orientation of the sextupole vertical axis. The correction coils are supported and electrically insulated from the main coil by insulating spacers. The alignment and assembly tolerances of the trim correction coils should not exceed the magnitude indicated as follows:

$\begin{array}{ll}\text { Coil displacement } & 0.25 \mathrm{~mm} \\ \text { Coil rotation } & 0.9 \mathrm{deg} \\ \text { Gap } & 0.9 \mathrm{deg} \\ \text { Elliptical deformation } & 0.25 \mathrm{~mm} \\ \text { Wire rms } & 0.125 \mathrm{~mm} \\ \text { Block rms } & 0.125 \mathrm{~mm}\end{array}$

3. Coils

Coils are wound with a (partially keystoned) flattened "Rutherford" cable arranged into two layers as shown in Fig. __. Each layer consists of an upper and lower winding. The four windings are connected in series. The cable strands are composed of NbTi superconducting filaments imbedded in copper with a minimum strand $j_{c}$ in superconductor (before cabling) of $2750 \mathrm{~A} / \mathrm{mm}^{2}$ (measured at $4.22 \mathrm{~K}, 5 \mathrm{~T}$ ). The design shall produce a magnetic field uniformity as specified in Table $I$. The essential cable parameters are as follows in Table IV:

Relatively low resistivity (a residual resistivity ratio of 30 at $6.6 \mathrm{~T}$ ) facing the beam is required to carry high frequency ( 1 kilohertz to several gigahertz) beam induced image current. Low impedance is required of the beam tube expansion joint. 
TABLE IV

\begin{tabular}{|c|c|c|c|}
\hline & $\begin{array}{l}\text { Inner } \\
\text { Coil }\end{array}$ & $\begin{array}{l}\text { Outer } \\
\text { Coil }\end{array}$ & \\
\hline Cable width & 0.366 & 0.383 & in \\
\hline Cable thick., narrow edge & 0.0522 & 0.0418 & in \\
\hline Cable thick., wide edge & 0.0625 & 0.0499 & in \\
\hline Keystone angle & 1.6 & 1.2 & deg \\
\hline Strand diameter & 0.0318 & 0.0255 & in \\
\hline No. of strands & 23 & 30 & \\
\hline Filament diameter & 5 & 5 & microns \\
\hline Filaments/strand & 11,000 & 6,000 & \\
\hline Cu/SC area ratio & $1.3 / 1$ & $1.8 / 1$ & \\
\hline
\end{tabular}

The cable is insulated with layers of Kapton tape and layer of fiberglass tape, with B-stage epoxy to hold the coll together during handling. The inner and outer coils are assembled with Kapton insulation and a Tefion slip-plane between and outside them. A strip heater is installed between the ID of the collar and outside diameter of coil. The strip heater is energized and fired during a quench to ensure that enough of the coil goes normal to prevent a localized hot spot that could damage the conductor or insulation.

\section{Collars}

Prior to assembly in the yoke, the coils are assembled in collars as shown in Fig. 1. These collars are to provide the necessary radial restraint to keep the coils under a positive compressive stress at operating conditions. This preload is necessary in order to maintain the positional tolerances required for the conductor under the influence of the Lorentz forces when the magnet is energized. 
The collars shall be made from laminations of nonmagnetic material with sufficiently high yield strength to contain assembled coils at the proper assembly pre-stresses. The laminations shall be relatively thin in radial width to obtain the maximum field contribution from the iron yoke consistent with field quality requirements. The coils are insulated from beam tube, strip heaters and collars with several layers of Kapton in order to provide the necessary spacing and dielectric strength to resist $2 \mathrm{kV}$ at operating conditions.

5. Yoke and Helium Containment Vessel

The magnet yoke consists of stacked iron laminations mounted in the helium containment shell as shown in Fig. 1. The iaminations are 10.5 inches in diameter and at a $6.6 \mathrm{~T}$ operating field contribute about $1.7 \mathrm{~T}$ to the central field. The stampings are punched with keyways to provide accurate positioning on the collared coil assembly which is mounted in the yoke. Two rectangular slots are provided in the laminations for the main bypass bus are located at the top and the correction coil leads at the bottom. The present concept calls for ultra low carbon (less than .008\%) sheet. The yoke laminations would be stacked in position. Longitudinal rods are inserted through the stacked laminations which are accurately weighed to achieve a weight uniformity consistent with the integral dipole field requirement. The rods are tensioned to compress the yoke slightly to maintain an accurate longitudinal dimension with the appropriate number of laminations required for meeting the weight tolerance.

The helium containment vessel is fabricated from stainless steel plate, and shall be capable of withstanding pressure developed during quench, and provide the necessary rigidity to keep the deflection of cold mass less than $0.5 \mathrm{~mm}$ between supports. Sets of holes are provided in the helium containment shells for the insertion of a series of fiducial marking plugs into recessed slots in the yoke. These plugs are sealed and are used as survey markers or indexing points for the magnet position. 


\section{Cryogenic Piping}

The magnet and cryostat assembly contains all of the pipes to interconnect the magnet refrigeration system through the ring magnet components around the circumference.

The first "pipe" is the complete single phase helium containment subassembly which delivers the supply cryogen which flows around the beam pipe and through the collared coil magnet assembly. The super critical helium at about $4 \mathrm{~atm}$ is passed into the magnet assembly; maximum helium temperature is $4.35 \mathrm{~K}$.

The second pipe is a stainless steel pipe operating at 4 atm and functions as a single phase helium return and recooler supply line.

The third pipe is a stainless steel pipe used as a $4.5 \mathrm{~K}$ one atmosphere, recooler helium boil-off gas return line.

The fourth pipe is an aluminum extrusion which is welded to the $20 \mathrm{~K}$ aluminum heat shield. This pipe connects to the helium relief header during system cooldown, or to the return or supply headers during operation. The cooldown is accomplished by flow of $200 \mathrm{~g} / \mathrm{s}$ of helium gas.

The fifth pipe is an aluminum extrusion which is welded to the $80 \mathrm{~K}$ heat shield. This pipe connects to the liquid nitrogen return or supply header.

7. Heat Shields, Insulation and Vacuum Vessel

The $4.35 K$ assembly is surrounded by concentric thermal shields, operating at $20 \mathrm{~K}$ and $80 \mathrm{~K}$, to reduce the radiant heat load on the cryogenic system. Shields are fabricated from aluminum flow channels and rolled shapes. 
Thermal insulation will be employed between the $300 \mathrm{~K}$ vacuum vesse 1 , $80 \mathrm{~K}$ shield and $20 \mathrm{~K}$ shield. The insulation blankets consist of multiple layers of aluminumized reflective plastic film separated by thin low-conductivity sheets of superinsulation. The $4.35 \mathrm{~K}$ assembly and thermal shields with their distributed static, dynamic and magnetic loads are supported relative to the vacuum vessel by a suspension system. This system must function under conditions that include cryostat assembly, magnet shipping and installation, cooldown and warmup, steady-state operation and upset (i.e., magnet quench, an internal pressure of 5 atmos. absolute, cryogenic fluid leakage, loss in insulating vacuum) situations. The suspension system employs compression post support members at five locations with the support-anchor at the cryostat mid-length. To provide the necessary controlled motion to compensate for the thermal contraction/expansion of the $4.35 \mathrm{~K}$ assembly and the supports, the supports, except at the central anchor, are mounted on sliding members. Sufficient transverse and rotational constraints are provided by the support assembly. The sagitta and constraint of the $4.35 \mathrm{~K}$ assembly in the horizontal direction is controlled by an additional mechanism at the base of the supports.

The $4.35 \mathrm{~K}$ assembly, thermal shields and suspension system are contained within, and supported relative to, the outer vacuum vessel. Vacuum vessel functions include the provision of thermal insulating vacuum, mechanical support and helium gas containment in the case of a leak in the 4 atms helium piping. The vessel material is steel to contain any existing fringe fields. The basic vessel cross section is cylindrical and is made of parts that permit the cold mass to be conveniently inserted. 
8. Magnet and Cryostat Interconnections

The ends of the magnet utilize straight pipe connections between the magnets. Interconnections between magnets include: beam tube, mechanical and electrical; $4.35 \mathrm{~K}$ helium pipe; $20 \mathrm{~K}$ and $80 \mathrm{~K}$ shields; and insulating vacuum. The connections incorporate bellows for magnet installation and thermal contraction. Thermal insulation is continuous across the end, thereby minimizing heat leak.

\section{Magnet Stands and Alignment}

The magnet stand supports the magnets from the tunnel floor and shall be a steel pedestal with provision for both vertical and horizontal adjustments. Vertical clearance shall be provided between the bottom of the vacuum vessel and the floor, and a distance of $70 \mathrm{~cm}$ is provided between centerlines of two magnet assemblies.

Stands will be located by survey and then bolted and grouted to the floor of the tunnel. An adjustment provision shall provide vertical, horizontal, and angular alignment. Clearance holes around the floor bolts allow for lateral and longitudinal alignment as well. Survey for the initial alignment will be accomplished using fiducial marks (provided during the magnet manufacturing operation) on the outside of the cryostat that are available at each support location. Alignment shall be accomplished within the following tolerances (rms) and excluding surveying tolerances:

Dipole
$\begin{array}{ll}\Delta x-r m s & 0.7 \mathrm{~mm} \text { (construction and alignment) } \\ \Delta y-r m s & 0.7 \mathrm{~mm} \text { (construction and alignment) } \\ \Delta 0-\mathrm{rms} & \pm 0.6 \mathrm{mrad}\end{array}$




\section{Structural Requirements}

The magnet assembly shall be capable to withstand, in addition to operational loads, in-place seismic, transportation, and handling at installation loads as follows:

- Seismic

Horizontal and vertical design spectra shown in NRC Regulatory Guide 1.61 scaled by 0.3 should be used as interim design seismic criteria. Criteria will be modified when specific site is known. Selected $0.3 \mathrm{~g}$ value approximates 300 year return period at most sites.

- Transportation

$\begin{array}{ll}\text { Vertical } & \pm 2.0 \mathrm{~g} \\ \text { Lateral } & \pm 1.0 \mathrm{~g} \\ \text { Axial } & \pm 1.5 \mathrm{~g}\end{array}$

- Handling and installation are not to exceed transportation loads. The single phase helium assembly shall be supported by cryostat system. Deflections of single phase assembly shall be limited to .020 inches in relation to suspension points.

The structural design shall be based on elastic behavior of all constituent material throughout all operating conditions except as noted for nonmetallic materials.

Factors of Safety for Structural Components shall be developed from limits as defined below: 


Item
Membrane Stresses, om
Bending Stresses, ob
Membrane + Bending
Ultimate Stresses
(General)
Ultimate Stresses
(Supports)
Seismic Stress
Buckling Analysis
(Safety Factors)
Stress Cycles

Item

Membrane Stresses, om

Bending Stresses, ob

Membrane + Bending

Ultimate Stresses

Stress Cycles

*In case of composite and non-metallic materials, principal stresses shall be limited to $20 \%$ of material ultimate strength.

The cryostat and the containment components shall be designed to the intent of ASME Boiler and Pressure Vessel Code, Section VIII, Div. II.

The magnet assembly shall be designed to withstand operational cycles per Section G.2.

\section{E. Availability/Reliability}

The Magnet System is the most critical component of the SSC as far as the operating availability is concerned.

In order to achieve the ultimate SSC operational Availability goal of 80\%, the Magnet System Availability has to be (including dipoles and quadrapoles) better than 0.98 . 
The above availability assuming Mean Time To Restore (MTTR) of five days requires 245 days between failures (MTBF) for the system.

Corresponding Mean Time Before Failure (MTBF) for individual magnets is

approximately $2.4 \times 10^{6}$ days and minimum reliability of .99989 .

\section{G. Design Life and Operating Cycles}

\section{Design Life}

The Magnet System shall be capable of operating at full current for a period of ten years over a twenty year life.

\section{Operating Cycles}

a. Thermal Cycles

The assembly shall be designed for twenty (20) thermal cycles defined as cooldown from $300 K$ to $4 K$ followed by warmup to $300 k$.

b. Quench Cycles

The assembly shall be designed for fifty (50) magnet quenches with all half cell coils quenching simultaneously.

c. Magnetic Cycles

The assembly shall be designed to withstand $10^{4}$ magnetic cycles.

H. Environment

1. Storage Environment

The assembly shall be capable of storage for a period of four years. External environment may vary over a temperature range from $0^{\circ} \mathrm{C}$ to $+40^{\circ} \mathrm{C}$ with humidity variation $10 \%$ - $90 \%$. During storage $80 \%$ of the time storage temperature will be maintained between $10^{\circ}-30^{\circ} \mathrm{C}$. 
2. Radiation Environment

Assembly shall be designed to withstand a dose of $1 \times 10^{8} \mathrm{rad}$.

3. Installation Environment

Assembly shall be designed for installation in the tunnel with temperature variations of $10^{\circ} \mathrm{C}$ to $37^{\circ} \mathrm{C}$ and a relative humidity of 90\%.

I. Maintenance

Magnet assembly shall be designed to be essentially maintenance free and shall be capable of removal and replacement in 24 hours.

K. Interface Systems, Functions and Services

The Magnet System interfaces functionally or physically with the following SSC Systems:
a. Magnet Power Supplies
b. Cryogenic System
c. Vacuum System
d. RF System
e. Abort System
f. Beam Instrumentation
g. Injection System
h. Control System
i. Safety System
j. Tunnel and Conventional Systems
k. Detectors 


\section{Quality Assurance}

The Magnet System is considered to be the most critical system of the collider as far as operating availability is concerned and requires strict compliance to the Reliability and Quality Assurance Program.

The Quality Assurance Plan for the Magnet System will adhere to the QA guidelines of the SSC QA Program and meet applicable requirements of ANSI/ASME - NQA-1 and DOE Order 5700.6A. Appendix 35.1 and 3A-1.

\section{Safety}

\section{N. Applicable Codes and Standards}

Applicable nationally recognized codes and standards will be used as guidelines in the design, manufacture and operation of the Magnet System. The codes and standards to be implemented appear below. Where existing codes cannot be used, project standards will be formulated and applied for design or vendor control.

\section{ASME}

ANSI

AWS

ASTM

AISC

AIEE

NEMA

IEEE

OSHA

ANSI Y74.5 shall be used for dimensioning and tolerancing of engineering drawings. 